\title{
Dissolution and Transport of TNT, RDX, and Composition B in Saturated Soil Columns
}

\author{
Katerina M. Dontsova,* Sally L. Yost, Jiri Šimunek, Judith C. Pennington, and Clint W. Williford
}

\begin{abstract}
Low-order detonations and blow-in-place procedures on military training ranges can result in residual solid explosive formulations to serve as distributed point sources for ground water contamination. This study was conducted to determine if distribution coefficients from batch studies and transport parameters of pure compounds in solution adequately describe explosive transport where compounds are present as solid particles in formulations. Saturated column transport experiments were conducted with 2,4,6-trinitrotoluene (TNT), hexahydro1,3,5-trinitro-1,3,5-triazine (RDX), and the explosive formulation, Composition B (Comp B) $(59.5 \pm \mathbf{2 . 0} \%$ RDX, $39.5 \pm 2.3 \%$ TNT, and $1 \%$ wax) in solid and dissolved forms. The two soils used were Plymouth loamy sand (mesic, coated Typic Quartzipsamments) from Camp Edwards, MA and Adler silt loam (coarse-silty, mixed, superactive, thermic Fluvaquentic Eutrudepts) from Vicksburg, MS. Interrupted flow experiments were used to determine if explosives were at equilibrium distribution between soil and solution phases. The HYDRUS-1D code was used to determine fate and transport parameters. Results indicated that sorption of high explosives was rate limited. The behavior of dissolved Comp B was similar to the behavior of pure TNT and RDX. Behavior of solid Comp B was controlled by dissolution that depended on physical properties of the Comp B sample. Adsorption coefficients determined by HYDRUS-1D were different from those determined in batch tests for the same soils. Use of parameters specific to formulations will improve fate and transport predictions.
\end{abstract}

Tow-ORDER (INCOMPLETE) DETONATIONS and blow-in-

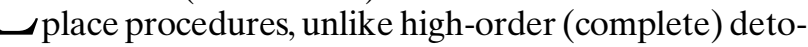
nations, can leave considerable explosives residue on military training ranges (Pennington et al., 2002). Such residues are potentially available to impact environmental and human receptors. Accurate transport parameters, such as soil-water partition coefficients $\left(k_{\mathrm{d}} s\right)$ and dissolution and degradation rates are essential for predicting transport to groundwater.

Batch-determined fate and transport parameters for explosives commonly used by the military were reviewed by Brannon and Pennington (2002). Existing models for predicting environmental fate of explosives rely on information obtained in batch tests with pure explosive compounds (Pennington and Patrick, 1990; Comfort et al., 1995; Xue et al., 1995; Price et al., 1997; Brannon et al., 1998; Price et al., 2001a; Price et al.,

K.M. Dontsova and C. Williford, Dep. of Chemical Engineering, Univ. of Mississippi, Oxford, MS. K.M. Dontsova, duty station: U.S. Army Engineer Research and Development Center, 3909 Halls Ferry Rd., Vicksburg, MS 39180. S. Yost, Computer Sciences Corporation, Vicksburg, MS. J. Šimunek, Univ. of California, Riverside. J. Pennington, Environmental Processes Branch, Environmental Laboratory, U.S. Army Engineer Research and Development Center, Vicksburg, MS. Received 5 Jan. 2006. *Corresponding author (Kateryna.Dontsova@ gmail.com).

Published in J. Environ. Qual. 35:2043-2054 (2006).

Technical Reports: Ground Water Quality

doi:10.2134/jeq2006.0007

(c) ASA, CSSA, SSSA

677 S. Segoe Rd., Madison, WI 53711 USA 2001b; Brannon et al., 2002; Brannon et al., 2005). However, explosives are typically formulated in combinations of two or more compounds with waxes, stabilizers, and binders. Binders and waxes have been shown to decrease dissolution rates of individual explosive compounds from formulations (Lynch et al., 2002b; Phelan et al., 2002). The effects of formulation on other fate and transport processes are unknown.

Solid particles ranging in size from small $(<2 \mathrm{~mm})$ to large (up to the diameter of the projectile) may be deposited on the soil surface when projectiles fail to detonate completely (a low-order detonation) (Pennington et al., 2005; Jenkins et al., 2006). Similar residues can be deposited when duds or unexploded ordnance that are disposed of by detonation in place fail to detonate completely. These failures result in locally scattered chunks of Comp B on the soil surface (Jenkins et al., 2006). An understanding of transport behavior of the components of this residue is necessary because of detections of one component of Comp B, RDX, in groundwater of military training ranges (USEPA, 1997).

This study focused on Comp B, one of the primary explosive formulations currently used in artillery projectiles and many other munitions. To accurately represent field conditions, residues from deliberate low-order detonations of Comp B-filled artillery shells were used. The objective was to determine transport parameters for TNT and RDX from solid phase Comp B under saturated conditions. The parameters for solid Comp B were compared with those for pure RDX and TNT; RDX and TNT in dissolved Comp B; and with adsorption coefficients determined in batch tests.

\section{MATERIALS AND METHODS \\ Soils}

Plymouth loamy sand (mesic, coated Typic Quartzipsamments) and Adler silt loam (coarse-silty, mixed, superactive, thermic Fluvaquentic Eutrudepts) were the soils used for this experiment. Adler silt loam samples were collected in Vicksburg, MS, whereas Plymouth loamy sand samples were collected at Camp Edwards, MA (Massachusetts Military Reservation [MMR]). Soil samples were collected to a depth of $20 \mathrm{~cm}$. Soils were air-dried, ground, and passed through a 2-mm sieve, and analyzed for cation exchange capacity (CEC) using the NaAc method (USEPA, 1986) and organic carbon (OC) by combustion after acid pretreatment. Analyses were

\footnotetext{
Abbreviations: ADNTs, amino-dinitrotoluenes (2ADNT, 2-amino-4,6dinitrotoluene and 4ADNT, 4-amino-2,6-dinitrotoluene); ARAMS, Army Risk Assessment Modeling System; CEC, cation exchange capacity; Comp B, Composition B; DNX, hexahydro-1,3-dinitroso-5-nitro1,3,5-triazine; HMX, octahydro-1,3,5,7-tetranitro-1,3,5,7-tetrazocine; HPLC, high performance liquid chromatography; $k_{\mathrm{d}}$, adsorption coefficient; MMR, Massachusetts Military Reservation; MNX, hexahydro1-nitroso-3,5-dinitro-1,3,5-triazine; OC, organic carbon; OM, organic matter; RDX, hexahydro-1,3,5-trinitro-1,3,5-triazine; TNT, 2,4,6-trinitrotoluene; TNX, hexahydro-1,3,5-trinitroso-1,3,5-triazine.
} 
performed by the Environmental Chemistry Branch of ERDC in Omaha, NE. Particle size was determined by the hydrometer method (Gee and Or, 2002). The Mississippi State University Extension Service Soil Testing Laboratory analyzed soil $\mathrm{pH}$ in 1:1 soil/water slurry, exchangeable cations, and base saturation. Results of characterizations are listed in Table 1. Soils had similar CEC despite differences in texture, possibly due to the greater OC content of Plymouth soil. Both soils had relatively low $\mathrm{OC}$ and clay content. High $\mathrm{pH}$ and $\mathrm{Ca}$ (not shown) indicated the presence of carbonates in Adler soil.

\section{Column Design}

Six flux-controlled flow-through columns were used in this study. They consisted of $10.16-\mathrm{cm}$ internal diameter by $17.00-\mathrm{cm}$ height stainless steel cylinders fitted with Media Grade 100 porous 316 stainless steel plates (Mott Corporation, Farmington, CT) and caps on the top and the bottom. Aqueous tracer or explosives solution was input via a valve in the top. Flow from top to bottom was selected so that solid test material (Comp B) could be easily introduced. The top was also equipped with a bleeder valve. A valve in the bottom cap allowed for free drainage of solution. A Fisherbrand Ultralow-Flow Peristaltic Pump (Fisher Scientific Houston, TX) was attached to the top of the column to supply solution at target solution flux. Outflow samples were collected continuously into $20-\mathrm{mL}$ vials using an automatic fraction collector with 50-vial capacity.

To ensure even distribution of the soil and to minimize preferential flow, soils were poured into columns in small amounts at a time and manually pressed. Average packed bulk density (BD) was $1.27 \mathrm{~g} \mathrm{~cm}^{-3}$ for Adler soil, and $1.60 \mathrm{~g} \mathrm{~cm}^{-3}$ for Plymouth soil. Bulk density was determined from the dry mass of soil used to pack a column of known volume.

\section{Saturated Flow Experiments}

Columns were saturated from the bottom with $0.005 \mathrm{M}$ $\mathrm{CaBr}_{2}$ solution for $4 \mathrm{~h}$. Pore volume was determined during saturation as the volume of solution necessary to fill the packed column. Columns were then connected to the pump on the top and flow was started. Outflow was monitored to determine volumetric flow rate. Once a constant flow rate was established (target flow rate was $1.18 \mathrm{~mL} \mathrm{~min}^{-1}$, or solution flux of $0.87 \mathrm{~cm}$ $\mathrm{h}^{-1}$; measured average flow rate was $1.09 \mathrm{~mL} \mathrm{~min}^{-1}$, or solution flux of $0.8 \mathrm{~cm} \mathrm{~h}^{-1}$ ), one pore volume of solution was pumped through the column to assure uniform flow (Gaber et al., 1995). The selected water flux was lower than the saturated hydraulic conductivities for both soils and about $20 \%$ of the average 1-yr rainfall intensity $\left(4 \mathrm{~cm} \mathrm{~h}^{-1}\right)$ for the eastern United States. Flow then was switched to solutions of RDX, TNT, or Comp B; solid Comp B was placed directly on the soil surface. Target concentrations of military grade RDX and TNT were $10 \mathrm{mg} \mathrm{L}^{-1}$; measured concentrations were $10.03 \mathrm{mg} \mathrm{L}^{-1}$ and $9.4 \mathrm{mg} \mathrm{L}^{-1}$, respectively. Composition $\mathrm{B}$ solution had an RDX concentration of $6.87 \mathrm{mg} \mathrm{L}^{-1}$, TNT of $3.28 \mathrm{mg} \mathrm{L}^{-1}$, and octahydro-1,3,

Table 1. Selected properties of the studied soils.

\begin{tabular}{|c|c|c|c|c|c|c|c|c|}
\hline Soil & $\mathbf{B D} \dagger$ & CEC & OC & Sand & Silt & Clay & pH & BS \\
\hline & $\mathrm{g} \mathrm{cm}^{-3}$ & $\mathrm{cmol}_{\mathbf{c}} \mathrm{kg}^{-1}$ & & $-\mathrm{gk}$ & -1 & & & $\%$ \\
\hline $\begin{array}{l}\text { Adler silt } \\
\text { loam }\end{array}$ & 1.18 & 7.83 & 2.0 & 114 & 841 & 45 & 8.2 & 100 \\
\hline $\begin{array}{l}\text { Plymouth } \\
\text { loamy } \\
\text { sand }\end{array}$ & 1.43 & 7.05 & 7.8 & 875 & 75 & 50 & 5.1 & \\
\hline
\end{tabular}

$\dagger \mathrm{BD}=$ field bulk density; $\mathrm{CEC}=$ cation exchange capacity by sodium acetate method; $\mathrm{OC}=$ organic carbon by combustion after acid treatment; $\mathbf{B S}=$ base saturation. 5,7-tetranitro-1,3,5,7-tetrazocine (HMX) of $0.58 \mathrm{mg} \mathrm{L}^{-1}$. Octahydro-1,3,5,7-tetranitro-1,3,5,7-tetrazocine is an impurity in Comp B typically at 1 to $10 \%(3.5 \%$ in our Comp B).

Radiolabeled ${ }^{14} \mathrm{C}$-RDX and ${ }^{14} \mathrm{C}$-TNT were added as tracers to the bulk solutions (specific activity of RDX was $7.68 \mathrm{mCi}$ $\mathrm{mmol}^{-1}$ and TNT $4.08 \mathrm{mCi} \mathrm{mmol}^{-1}$ ) at $0.145 \%$ for $\mathrm{RDX}$ in solution and $0.278 \%$ for TNT. The radiotracer allowed easy monitoring of explosives concentrations in outflow as the experiment progressed.

For the solid Comp B treatment, steady-state flow was briefly stopped so that $10.0 \mathrm{~g}$ of low-order detonation residues containing solid Comp B (65\% Comp B and 35\% nonexplosive debris, primarily soil particles) between 2 layers of glass wool could be placed on the surface of the soil. Solid Comp B was a composite of the 0.25 - to $2-\mathrm{mm}$ size fractions of residue from low-order detonation experiments conducted for another project (Pennington et al., 2005). In that project, detonations were performed on a large tarp so that residue could be recovered by sweeping. Therefore, residues were relatively clean except for uncontaminated soil introduced via occasional shrapnel tears in the tarp. The explosives component included $57.6 \%$ RDX, 38.9\% TNT, and 3.5\% HMX. Flow was resumed at the same rate as soon as solid Comp B residues were in place.

After four to six pore volumes of explosive solutions, flow was switched back to the background solution (or solid Comp $\mathrm{B}$ was removed), which was applied for another four to six pore volumes. For every soil and explosive treatment two experiments were conducted. In one, flow was uninterrupted, whereas in the other, flow was interrupted for 12 to $24 \mathrm{~h}$ to allow explosives to equilibrate with the soil. During flow interruption both inflow and outflow from the column were stopped and the column remained saturated. Flow interruption techniques are often used to elucidate rate-limited sorption processes (Murali and Aylmore, 1980; Fortin et al., 1997; Šimunek et al., 2002).

Outflow samples were analyzed using high performance liquid chromatography (HPLC) (Waters HPLC, GenTech Scientific, Arcade, NY) and liquid scintillation (Tri-Carb 2500TX Liquid Scintillation Analyzer, PerkinElmer Life and Analytical Sciences, Boston, MA). Every fifth sample (approximately every $0.1 \mathrm{~L}$ ) was analyzed by scintillation counting and every 20th (approximately every 0.4 L) by HPLC. Standard USEPA Method 8330 (HPLC) (USEPA, 1994) was used with the addition of HMX and the following degradation products: monoand diamino-nitrotoluenes and azoxy dimers of TNT, and mono-, di-, and trinitroso derivatives of RDX. Detection limits were $20 \mu \mathrm{g} \mathrm{L}^{-1}$ for TNT, HMX, 2-amino-4,6-dinitrotoluene (2ADNT), and 4-amino-2,6,-dinitrotoluene (4ADNT); $200 \mu \mathrm{g}$ $\mathrm{L}^{-1}$ for RDX and $50 \mu \mathrm{g} \mathrm{L}{ }^{-1}$ for RDX degradation products. Concentrations of explosives in solid Comp $\mathrm{B}$ residue were determined by shaking $5 \mathrm{~g}$ of residue with $150 \mathrm{~mL}$ acetonitrile in 3 sequential extractions followed by filtering $(45-\mu \mathrm{m}$ GF filter) and HPLC analysis.

To determine the longitudinal dispersivity $(\lambda)$ for each soil and monitor for signs of preferential flow, all solutions were prepared with ${ }^{3} \mathrm{H}_{2} \mathrm{O}$ tracer (Selim et al., 1995). Specific activity of ${ }^{3} \mathrm{H}_{2} \mathrm{O}$ was $2.18 \mathrm{mCi} \mathrm{mmol}^{-1}$ with $1.239 \times 10^{-6} \%$ of ${ }^{3} \mathrm{H}_{2} \mathrm{O}$ in solution. Liquid scintillation was used to measure tritium activity.

\section{Numerical Analysis}

Experiments were analyzed using the HYDRUS-1D code for simulating the one-dimensional movement of water, heat, and multiple solutes in variably saturated porous media (Šimunek et al., 2005). Minimization of the objective function that includes the sum of squared deviations between measured 
and simulated concentrations was performed by the LevenbergMarquardt nonlinear minimization algorithm (Marquardt, 1963). The following models were used in analysis: convectiondispersion equation for ${ }^{3} \mathrm{H}_{2} \mathrm{O}$ tracer and two-site sorption model (with decay) (chemical nonequilibrium model) for explosives and their degradation products.

\section{Transport of Nonreactive Solute}

Transport of the ${ }^{3} \mathrm{H}_{2} \mathrm{O}$ tracer can be described using the convection-dispersion equation for constant water content, flux density, and dispersion coefficient:

$$
\theta \frac{\partial c}{\partial t}=\theta D \frac{\partial^{2} c}{\partial z^{2}}-q \frac{\partial c}{\partial z}
$$

where $c$ is the solute concentration $\left(\mu \mathrm{g} \mathrm{cm}{ }^{-3}\right), q$ is the convective flux $\left(\mathrm{cm} \mathrm{h}^{-1}\right), \theta$ is the water content $\left(\mathrm{cm}^{3} \mathrm{~cm}^{-3}\right)$ equal to porosity for saturated experiments, $z$ is the spatial coordinate $(\mathrm{cm}), t$ is time $(\mathrm{h})$, and $D$ is the dispersion coefficient $\left(\mathrm{cm}^{2} \mathrm{~h}^{-1}\right)$ assumed to be the product of the longitudinal dispersivity, $\lambda(\mathrm{cm})$, and $q$ divided by $\theta$.

\section{Two-Site Sorption Model (with Decay)}

The concept of two-site sorption (Selim et al., 1976; van Genuchten and Wagenet, 1989) that permits consideration of nonequilibrium adsorption-desorption reactions was used to describe the transport of explosives. The two-site sorption concept assumes that the sorption can be divided into two parts:

$$
s=s_{\mathrm{e}}+s_{\mathrm{k}}
$$

Sorption, $s_{\mathrm{e}}\left(\mu \mathrm{g} \mathrm{g}^{-1}\right)$, on one fraction of the sites (the Type-1 sites) is assumed to be instantaneous, whereas sorption, $s_{\mathrm{k}}$ $\left(\mu \mathrm{g} \mathrm{g}^{-1}\right)$, on the remaining (Type-2) sites is considered to be time-dependent.

Sorption on the Type-2 nonequilibrium sites is assumed to be a first-order kinetic rate process. The mass-balance equation for the Type- 2 sites in the presence of degradation is given by:

$$
\frac{\partial s_{\mathrm{k}}}{\partial t}=\omega\left[(1-f) k_{\mathrm{d}} c-s_{\mathrm{k}}\right]-\mu_{\mathrm{s}} s_{\mathrm{k}}
$$

where $f$ is the fraction of exchange sites assumed to be in equilibrium with the solution phase $(-), k_{\mathrm{d}}$ is the linear distribution coefficient $\left(\mathrm{cm}^{3} \mathrm{~g}^{-1}\right), \mu_{\mathrm{s}}$ is first-order rate coefficient in the solid phase $\left(\mathrm{h}^{-1}\right)$, and $\omega$ is a first-order kinetic rate constant for sorption to kinetic sites $\left(\mathrm{h}^{-1}\right)$. A linear distribution coefficient was used because the majority of explosive compounds exhibit linear sorption by soils (Pennington et al., 1999) and our preliminary batch studies showed that 3 out of 4 studied isotherms were linear. The governing transport equation is then as follows for constant water content, flux density, dispersion coefficient, bulk density, and distribution coefficient:

$$
\begin{gathered}
\theta \frac{\partial c}{\partial t}+\rho f k_{\mathrm{d}} \frac{\partial c}{\partial t}+\rho \frac{\partial s_{\mathrm{k}}}{\partial t}=\theta D \frac{\partial^{2} c}{\partial z^{2}}-q \frac{\partial c}{\partial z}-\mu_{\mathrm{w}} \theta c \\
-\mu_{\mathrm{s}} \rho f k_{\mathrm{d}} c-\mu_{\mathrm{s}} \rho s_{\mathrm{k}}+\gamma \theta
\end{gathered}
$$

where $\rho$ is bulk density $\left(\mathrm{g} \mathrm{cm}^{-3}\right), \mu_{\mathrm{w}}$ is first-order rate coefficient in the liquid phase $\left(\mathrm{h}^{-1}\right)$, and $\gamma$ is the zero-order rate coefficient that we used to account for dissolution of solid Comp B $\left(\mu \mathrm{g} \mathrm{cm}^{-3} \mathrm{~h}^{-1}\right)$. In Eq. [4] the first-order rate coefficients $\mu_{\mathrm{s}}$ and $\mu_{\mathrm{w}}$ lump all removal mechanisms of the parental compound, such as irreversible sorption and decay. Complicated attenuation processes of TNT that include covalent bonding of decomposition products to soil organic matter functional groups make separation of irreversible sorption and decay difficult.
Coefficients $\mu_{\mathrm{w}}$ and $\mu_{\mathrm{s}}$ were set to be equal for this experiment because adsorbed explosives can decay (Achtnich and Lenke, 2001; Balakrishnan et al., 2004) and setting decay coefficients equal decreased the number of fitted parameters. Only $\mu_{w}$ is reported further in the paper. Dissolution was modeled as a zero-order production process of limited duration. It was assumed that during the time when Comp B was present at the top of the profile, there was a zero-order production process in a small layer close to the top boundary.

\section{Parameter Estimation}

The numerical analysis of experimental data was performed as follows. First, the conservative tracer breakthrough curves were used to estimate the longitudinal dispersivity, $\lambda(\mathrm{cm})$. The chemical nonequilibrium model was then used to analyze explosives breakthrough curves. Longitudinal dispersivity was fixed at a value determined for tracer. The following parameters were estimated for explosives: fraction of sites with instantaneous adsorption, $f$, adsorption coefficient, $k_{\mathrm{d}}\left(\mathrm{g}^{-1} \mathrm{~cm}^{3}\right)$, firstorder rate coefficient for dissolved phase (degradation rate), $\mu_{\mathrm{w}}\left(\mathrm{h}^{-1}\right)$, and first-order rate coefficient for two-site nonequilibrium adsorption, $\omega\left(\mathrm{h}^{-1}\right)$. Radiotracer results gave an estimate of the movement of the total mixture of explosives without considering individual parent and/or daughter products, whereas HPLC measurements gave an estimate of the movement of TNT, RDX, and their transformation products. In ${ }^{14} \mathrm{C}$ radiotracer experiments the rate coefficients $\left(\mu_{\mathrm{w}}\right.$ and $\left.\mu_{\mathrm{s}}\right)$ corresponded to irreversible attenuation, whereas in HPLC experiments they corresponded to the sum of attenuation and degradation. In this paper, reversible adsorption was defined operationally as the process that allowed explosives to be transported further as a result of the desorption, whereas irreversible attenuation was defined as the process that made explosives unavailable for further transport. The production coefficient, $\gamma$, was fitted in HYDRUS-1D simulations for experiments with solid Comp B.

Mass-balance calculations were performed for the ${ }^{14} \mathrm{C}$ radiotracer and HPLC results (Table 2) by integration of each breakthrough curve. The accuracy of mass-balance estimates was evaluated using recovery of tritiated water as a conservative tracer.

The $R^{2}$ values and confidence intervals for fitted parameters were obtained by analyzing the correspondence between measured and fitted breakthrough concentrations and the behavior of the objective function around its minimum, respectively (Šimunek and Hopmans, 2002). Parameter estimates were considered significant if they were different from zero (confidence intervals did not intersect with zero). If parameter estimates were consistently nonsignificant, parameters were removed from the model. To improve the confidence in adsorption coefficients and dissolution rates, kinetic parameters ( $f$ and $\omega$ ) were removed from the model for solid Comp B experiments. However, if only a few parameter estimates were nonsignificant, these parameters were kept in the model, but not used to draw conclusions.

Interrupted and uninterrupted flow experiments were treated as replicates for the purposes of statistical analysis of transport parameters. For comparison between treatments, differences were considered significant when greater than the sum of standard errors of the means multiplied by 1.96 (for $95 \%$ probability).

\section{Batch Adsorption Studies}

Linear distribution coefficients determined from HYDRUS$1 \mathrm{D}$ simulations were compared to $k_{\mathrm{d}} s$ determined by five-point 
Table 2. Fraction of solutes recovered in outflow in the column transport experiments involving ${ }^{3} \mathrm{H}_{2} \mathrm{O},{ }^{14} \mathrm{C}$-TNT, ${ }^{14} \mathrm{C}$-RDX, and dissolved Composition B (Comp B) (57.6\% RDX, 38.9\% TNT, and 3.5\% HMX) in Adler and Plymouth soils.

\begin{tabular}{|c|c|c|c|c|c|c|c|c|c|}
\hline Soil & Treatment & ${ }^{3} \mathrm{H}_{2} \mathbf{O}$ & ${ }^{14} \mathrm{C}-\mathrm{RDX}$ & $\mathbf{R D X} \dagger$ & RDX + products & ${ }^{14} \mathrm{C}-\mathrm{TNT}$ & TNT & TNT + products & HMX \\
\hline \multirow[t]{2}{*}{ Adler } & RDX & 0.99 & 0.98 & NA & NA & NA & NA & $\mathbf{N A}$ & $\mathbf{N A}$ \\
\hline & RDX IF & 1.05 & 1.05 & NA & NA & NA & NA & NA & NA \\
\hline \multirow[t]{2}{*}{ Plymouth } & RDX & 0.94 & $0.88(0.91) \S$ & NA & NA & NA & NA & $\mathbf{N A}$ & NA \\
\hline & RDX IF & 1.00 & 0.81 & NA & NA & NA & NA & NA & $\mathbf{N A}$ \\
\hline \multirow[t]{2}{*}{ Adler } & TNT & 0.99 & NA\# & NA & NA & 0.73 & 0.07 & 0.29 & NA \\
\hline & TNT IF & 1.04 & $\mathbf{N A}$ & NA & NA & 0.75 & 0.15 & 0.35 & NA \\
\hline \multirow[t]{2}{*}{ Plymouth } & TNT & 0.97 & NA & NA & NA & $0.36(0.42) \S$ & 0.01 & 0.04 & $\mathbf{N A}$ \\
\hline & TNT IF & 0.94 & NA & NA & NA & 0.41 & 0.03 & 0.05 & NA \\
\hline \multirow[t]{2}{*}{ Adler } & Comp B & 0.97 & 1.10 & 0.86 & 0.88 & NA & 0.06 & 0.22 & 1.02 \\
\hline & Comp B IF & 1.05 & 1.03 & 0.81 & 0.85 & NA & 0.03 & 0.07 & 0.96 \\
\hline \multirow[t]{2}{*}{ Plymouth } & Comp B & 0.98 & 1.05 & 0.89 & 0.89 & NA & 0.20 & 0.25 & 1.01 \\
\hline & Comp B IF & 1.11 & 1.05 & 0.90 & 0.91 & NA & 0.14 & 0.20 & 1.03 \\
\hline
\end{tabular}

$\dagger$ Mass balance was based on weight concentrations because of the similarity of molecular weights of TNT and some of its measured products. In addition, using molar concentrations for dimers, like azoxy compounds, would underestimate amount of TNT products.

$\doteqdot$ IF $=$ interrupted flow.

$\S$ Breakthrough was not complete, extrapolated value in parentheses was determined assuming the same slope for adsorption and desorption legs of the breakthrough curve.

\# Not applicable.

batch studies using RDX and TNT with ${ }^{14} \mathrm{C}$ radiolabel. Adsorption partitioning was conducted at a $4: 1$ solution/soil mass ratio in 25-mL glass centrifuge tubes. Triplicate samples and a blank were spiked at concentrations of $0.001,0.0025,0.005$, 0.0075 , and $0.01 \mu \mathrm{Ci} \mathrm{mL}^{-1}\left(37,92.5,185,277.5\right.$, and $\left.370 \mathrm{~Bq} \mathrm{~mL}^{-1}\right)$. Total explosive concentrations were 1 to $10 \mathrm{mg} \mathrm{L}^{-1} \mathrm{RDX}$ and 1 to $10 \mathrm{mg} \mathrm{L}^{-1}$ TNT. The samples were shaken for $24 \mathrm{~h}$ on a reciprocating shaker at 180 excursions per minute, centrifuged at 8288 relative centrifugal force (RCF) for $60 \mathrm{~min}$, and the aqueous phase removed and analyzed by liquid scintillation counting. Linear adsorption isotherms were determined from the solution concentrations and calculated sediment concentrations. Equilibration time was determined from kinetic adsorption curves established by shaking $10 \mathrm{mg} \mathrm{L}^{-1}$ radiolabeled RDX and TNT solutions with soils at 4:1 solution/soil mass ratio for $0,0.5,1,2,6,12$, and $24 \mathrm{~h}$, and $5 \mathrm{~d}$.

\section{RESULTS AND DISCUSSION \\ Batch Adsorption Studies}

The kinetic tests showed that RDX reached sorption equilibrium between soil and water within less than $2 \mathrm{~h}$. Fast sorption of RDX by soils was also reported previously (Xue et al., 1995; Singh et al., 1998). Therefore, 24-h equilibration was used in subsequent sorption studies for convenience. The RDX blank recovery was $101.1 \pm 1.0 \%$, indicating no sorption by the glassware or loss through other pathways. The TNT blank recovery was also complete $(99.3 \pm 1.3 \%)$. However, TNT distribution between soil and water did not stabilize over time, but continued to decline slightly even at $120 \mathrm{~h}$. Processes affecting TNT fate in soils may include TNT decomposition to products that tend to covalently bind to the soil organic matter resulting in their removal from solution (Thorn et al., 2002). Partition coefficients were determined at $24 \mathrm{~h}$ for comparisons with RDX coefficients.

The RDX sorption isotherms were linear (Fig. 1) in agreement with published reports (Xue et al., 1995; Singh et al., 1998; Tucker et al., 2002; Yamamoto et al., 2004). The $k_{\mathrm{d}}$ values determined from the isotherms $\left(0.48 \mathrm{~cm}^{3} \mathrm{~g}^{-1}\right.$ for Adler soil and $0.65 \mathrm{~cm}^{3} \mathrm{~g}^{-1}$ for Plymouth soil) were similar to values reported from shake tests with soils of comparable texture, OM content, and CEC (0.16 to $2.2 \mathrm{~cm}^{3} \mathrm{~g}^{-1}$, average of $0.93 \mathrm{~cm}^{3} \mathrm{~g}^{-1}$, median $0.92 \mathrm{~cm}^{3}$ $\mathrm{g}^{-1}$ ) (Brannon et al., 1992; Ainsworth et al., 1993; Xue et al., 1995; Myers et al., 1998; Pennington et al., 1999; Price et al., 2000).

The TNT sorption isotherm was linear for Plymouth soil and nonlinear for Adler (Freundlich $k_{\mathrm{f}}=3.9, n=$ $\left.1.4, R^{2}=0.99\right)$. However, to make comparisons between the soils and explosives, linear regression was fitted through the data. The TNT $k_{\mathrm{d}} s\left(2.4\right.$ and $1.6 \mathrm{~cm}^{3} \mathrm{~g}^{-1}$ for Adler and Plymouth, respectively) agree with values reported in the literature (Brannon and Pennington, 2002) for the same equilibration time and for soils with similar properties (average $1.8 \mathrm{~cm}^{3} \mathrm{~g}^{-1}$, median $1.1 \mathrm{~cm}^{3}$ $\mathrm{g}^{-1}$, range 0.27 to $4.5 \mathrm{~cm}^{3} \mathrm{~g}^{-1}$ ) (Brannon et al., 1992; Ainsworth et al., 1993; Xue et al., 1995; Myers et al., 1998; Pennington et al., 1999; Price et al., 2000).

\section{Conservative Tracer}

Hollow triangles in Fig. 2 and 3 represent measured values for outflow concentrations of the conservative tracer, ${ }^{3} \mathrm{H}_{2} \mathrm{O}$, labeled on figures as "measured water."

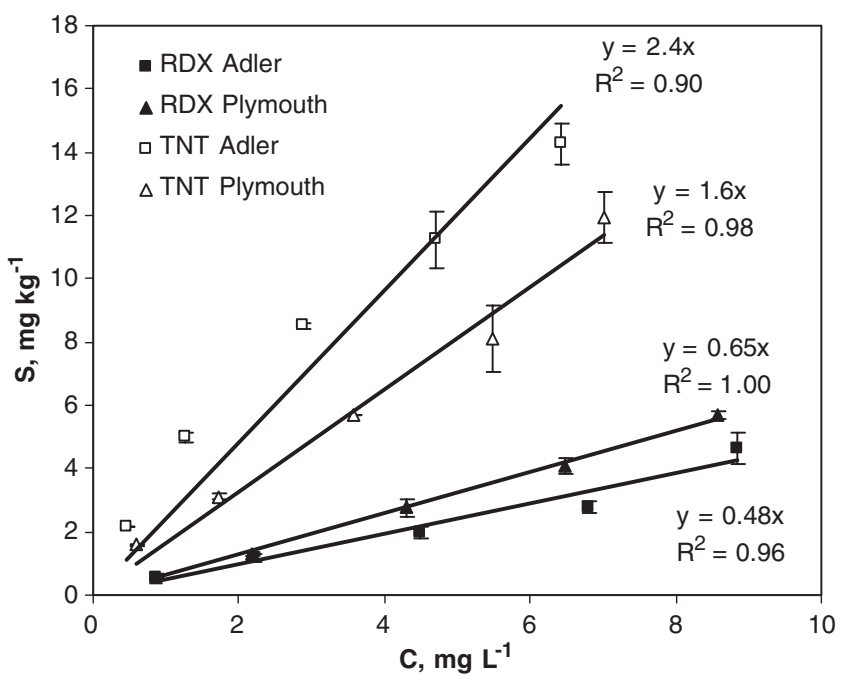

Fig. 1. Adsorption isotherms for TNT and RDX with Adler and Plymouth soils. C, measured solution concentration; $S$, calculated soil concentration. Error bars equal standard error of the mean. 

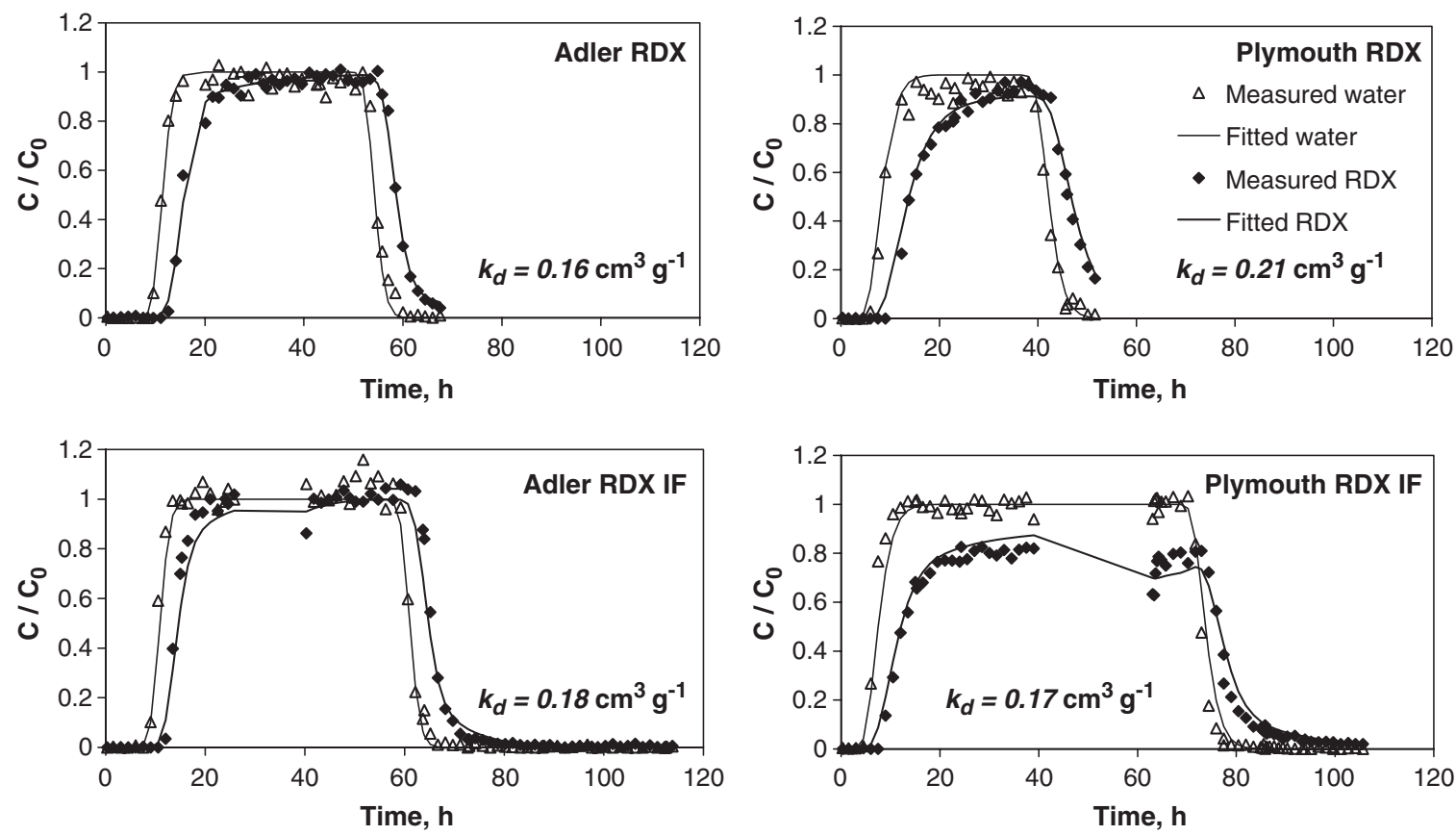

Fig. 2. Breakthrough curves for ${ }^{14} \mathrm{C}$-RDX and ${ }^{3} \mathrm{H}_{2} \mathrm{O}$ for Adler (left) and Plymouth (right) soils for continuous (top) and interrupted (bottom) flow experiments. IF, interrupted flow.

Dispersivity was larger for the coarser Plymouth soil $(0.62$ to $2.29 \mathrm{~cm})$ than for the finer Adler soil $(0.07$ to $0.17 \mathrm{~cm}$ ) (Table 3), but generally small as expected for short repacked columns.

Breakthrough of the conservative tracer occurred at one pore volume $(711 \mathrm{~mL}$ for Adler or $11 \mathrm{~h}$ and $519 \mathrm{~mL}$ for Plymouth or $8 \mathrm{~h}$ ), indicating the absence of preferential pathways for flow. No air entrainment within the column was observed. Breakthrough curves were plotted on a time basis to accurately present interrupted flow experiments. Outflow concentrations of ${ }^{3} \mathrm{H}_{2} \mathrm{O}$ resumed at similar values after the flow interruption, indicating that no or only limited physical nonequilibrium occurred in the soil column. Mass-balance calculations (Table 2) indicated that all tritiated water was recovered $(100 \pm 5 \%)$.

\section{RDX}

Solid diamonds represent measured values for the ${ }^{14} \mathrm{C}$-RDX radiotracer concentration for the two soils with and without interrupted flow (Fig. 2). For ${ }^{14} \mathrm{C}-\mathrm{RDX}$, breakthrough was observed later than for the conservative tracer indicating adsorption to the solid phase. The average $k_{\mathrm{d}}$ value determined from the curves was slightly larger for Plymouth than Adler soil, but the difference was not significant.

The ${ }^{14} \mathrm{C}-\mathrm{RDX}$ radiotracer exhibited little retardation, as is generally reported in the literature (Selim et al., 1995; Brannon and Pennington, 2002; Tucker et al., 2002). The $k_{\mathrm{d}}$ values for ${ }^{14} \mathrm{C}$-RDX determined from HYDRUS-1D (Table 3) were smaller than values determined in the batch experiments (Fig. 1). Batch adsorption coefficient values for Plymouth soil were similar to values reported by Speitel et al. (2002) for this soil. High mobility of
${ }^{14} \mathrm{C}-\mathrm{RDX}$ was supported by the mass balance (Table 2 ). For Adler soil, sorption was reversible; recovery of ${ }^{14} \mathrm{C}$-RDX varied between 98 and $105 \%$. Furthermore, irreversible attenuation was not statistically significant when modeled by HYDRUS-1D. However, for Plymouth soil, some irreversible attenuation was observed, as indicated by lower ${ }^{14} \mathrm{C}-\mathrm{RDX}$ recovery in outflow ( 81 to $91 \%$ ) and significant numbers for irreversible attenuation rate coefficient $\left(0.012 \pm 0.002 \mathrm{~h}^{-1}\right)$. Breakthrough curves also indicated that the outflow concentration was less than inflow for Plymouth soil, but similar to inflow concentration for Adler soil. Incomplete recovery of ${ }^{14} \mathrm{C}-\mathrm{RDX}$ in Plymouth soil is consistent with $8 \%$ unextractable ${ }^{14}$ C-RDX after 168 d observed by Singh et al. (1998) and irreversible attenuation of RDX in Plymouth (7.4\%) reported by Speitel et al. (2002).

The asymmetric shape of the breakthrough curves, particularly for Plymouth soil, and results of HYDRUS1D simulations suggest rate-controlled adsorption and desorption. An estimated $30 \%$ of adsorption sites in Adler soil and 33\% in Plymouth soil exhibited kinetic adsorption, with the rate of exchange in 0.12 to $0.16 \mathrm{~h}^{-1}$ range (Table 3 ). The decrease in concentration following flow interruption also indicated chemical nonequilibrium.

Outflow was not analyzed for RDX by HPLC because it was assumed that ${ }^{14} \mathrm{C}$-RDX accurately represents RDX in soil as there is little RDX degradation under aerobic conditions (Pennington and Brannon, 2002; Speitel et al., 2002).

\section{TNT}

The ${ }^{14} \mathrm{C}-\mathrm{TNT}$ radiotracer exhibited greater attenuation than ${ }^{14} \mathrm{C}$-RDX as indicated by a delay in the breakthrough curve and smaller outflow concentrations (Fig. 3). 

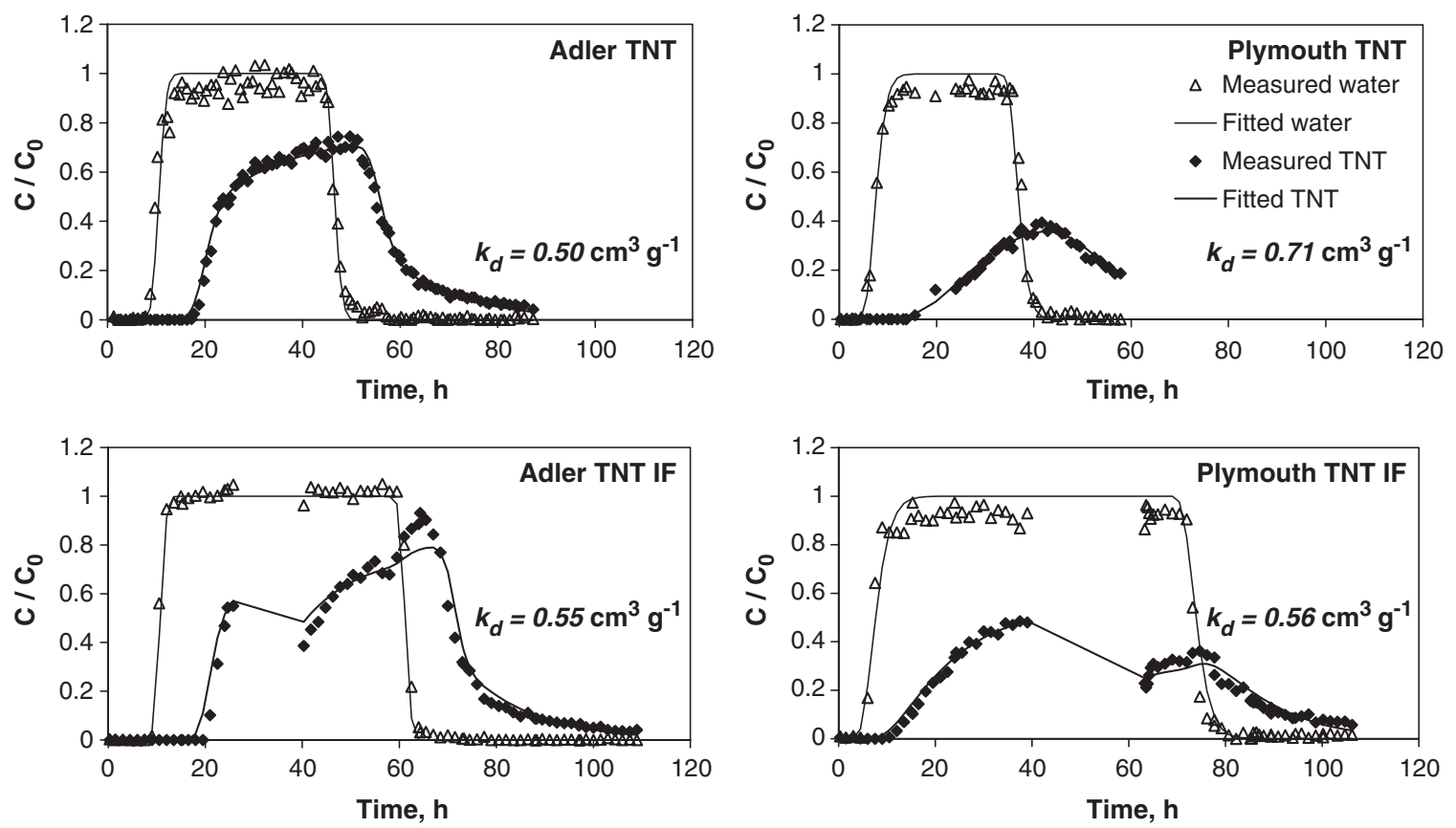

Fig. 3. Breakthrough curves for ${ }^{14} \mathrm{C}$-TNT and ${ }^{3} \mathrm{H}_{2} \mathrm{O}$ for Adler (left) and Plymouth (right) soils for continuous (top) and interrupted (bottom) flow experiments. IF, interrupted flow.

Part of the attenuation was attributed to reversible adsorption, and part to irreversible attenuation.

Average $k_{\mathrm{d}} s$ were 3.2 times greater for ${ }^{14} \mathrm{C}$-TNT than for ${ }^{14} \mathrm{C}$-RDX in both soils (Table 3 ) suggesting a greater affinity of TNT for adsorption sites. This difference was close to the 2.4-fold difference in $\log \mathrm{K}_{\mathrm{ow}}$ of the compounds (2.06 and 0.87 for TNT and RDX, respectively) suggesting that partitioning of TNT to the OM may be a significant mechanism for reversible adsorption.

For both soils, ${ }^{14} \mathrm{C}$-TNT $k_{\mathrm{d}} s$ were small compared to values reported in the literature (Brannon and Pennington, 2002) $\left(0.53\right.$ and $0.63 \mathrm{~cm}^{3} \mathrm{~g}^{-1}$ for Adler and Plymouth, respectively, difference not statistically significant). However, the irreversible attenuation contribution was considerable with the attenuation rate significantly smaller in Adler $\left(0.023 \pm 0.005 \mathrm{~h}^{-1}\right)$ than in Plymouth $\left(0.101 \pm 0.022 \mathrm{~h}^{-1}\right)$ soil. A 4.4 -fold difference in rate between soils was consistent with difference in OC content $(0.2$ and $0.78 \%$ for Adler and Plymouth soils, respectively), which is a matrix for irreversible attenuation (Thorn et al., 2002). The mechanism for irreversible attenuation of TNT involves reduction to amino transformation products, followed by covalent bonding to the functional groups, e.g., carboxylic acid, of OM (Thorn et al., 2002).

The ${ }^{14} \mathrm{C}$-TNT $k_{\mathrm{d}} s$ determined from batch shake tests (2.4 and $1.6 \mathrm{~cm}^{3} \mathrm{~g}^{-1}$ for Adler and Plymouth, respectively) and column experiments $\left(0.53\right.$ and $0.63 \mathrm{~cm}^{3} \mathrm{~g}^{-1}$ for Adler and Plymouth, respectively) differed. Batch $k_{\mathrm{d}} s$ were probably larger because they included irreversible attenuation and TNT is known to have a contribution of covalent bonding to total retention by soils (Thorn et al., 2002). Selim et al. (1995) found that adsorption coefficients for TNT obtained from batch ex- periments were larger than those obtained from column experiments and explained it by more complete mixing in batch experiments.

Asymmetric breakthrough curve, as well as the decrease in concentration when flow was interrupted, indicated rate-controlled sorption of ${ }^{14} \mathrm{C}$-TNT in agreement with Selim et al. (1995). Similar to ${ }^{14} \mathrm{C}-\mathrm{RDX},{ }^{14} \mathrm{C}$-TNT adsorption was instantaneous to a greater fraction of sites in Adler (0.63) than in Plymouth (0.38) soils. Both kinetic sorption and retarded nonlinear intra-particle diffusion (Fesch et al., 1998) may be causing nonequilibrium effects in TNT transport in soils. Rate of sorption $(\omega)$ accounts for both forms of the nonequilibrium.

Outflow concentrations of HPLC-measured TNT in Plymouth soil were small and inconsistent and, therefore, were not used for the simulation. However, for Adler soil TNT $k_{\mathrm{d}} s$ were similar to the values for the ${ }^{14} \mathrm{C}$-TNT radiotracer, whereas degradation was considerably greater, because HPLC-measured TNT included both irreversible attenuation and degradation (Table 3). Estimates for kinetic parameters $(f$ and $\omega)$ in HPLCmeasured TNT breakthroughs were nonsignificant. The limited number of samples analyzed by HPLC combined with the selection of samples with non-zero TNT concentrations (and error) resulted in larger confidence intervals and lower $R^{2}$.

Mass-balance calculations for ${ }^{14} \mathrm{C}$-TNT were consistent between similar treatments (Table 2). Seventy-three to seventy-five percent of ${ }^{14} \mathrm{C}$-TNT was recovered in Adler and 41 to $42 \%$ in Plymouth soil. Speitel et al. (2002) reported that 74 to $85 \%$ of ${ }^{14} \mathrm{C}$-TNT radiotracer was recovered for the subsoil coming from MMR, which is the same soil as Plymouth. For other soils, 20 to 50\% of added TNT was reported to be unextractable (Comfort 
Table 3. Solute transport parameters obtained by HYDRUS-1D for column saturated flow experiments involving ${ }^{3} \mathrm{H}_{2} \mathrm{O},{ }^{14} \mathrm{C}$-TNT, ${ }^{14} \mathrm{C}$ RDX, and dissolved and solid Composition B (Comp B) (57.6\% RDX, 38.9\% TNT, and 3.5\% HMX) in Adler and Plymouth soils $\left(\theta\right.$ was determined from the weight of water needed to saturate the column, $\lambda$ was estimated from ${ }^{3} \mathbf{H}_{2} \mathbf{O}$, whereas $f, k_{\mathrm{d}}$, $\mu_{w}, \omega$, and $\gamma$ from explosives).

\begin{tabular}{|c|c|c|c|c|c|c|c|c|c|c|}
\hline \multicolumn{2}{|l|}{ Parameter } & $\theta \dagger$ & $\boldsymbol{\lambda}$ & $R^{2}$ & $f$ & \multirow{2}{*}{$\frac{k_{\mathrm{d}}}{\mathrm{cm}^{3} \mathrm{~g}^{-1}}$} & $\mu_{w}$ & $\omega$ & \multirow{2}{*}{$\frac{\gamma}{\mu \mathrm{g} \mathrm{cm}^{-3} \mathrm{~h}^{-1}}$} & \multirow[t]{2}{*}{$R^{2}$} \\
\hline & & \multicolumn{3}{|c|}{ cm } & & & ${ }^{-}$ & & & \\
\hline \multicolumn{11}{|c|}{ RDX solution phase } \\
\hline \multirow[t]{3}{*}{${ }^{14} \mathrm{C}-\mathrm{RDX}$} & Adler & $\mathbf{0 . 5 3} \pm \mathbf{0 . 0 0 8}$ & $0.17 \pm 0.004$ & 0.99 & $\mathbf{0 . 7 0} \pm \mathbf{0 . 0 1}$ & $\mathbf{0 . 1 7} \pm \mathbf{0 . 0 1}$ & $\mathbf{0 . 0 0 0} \pm \mathbf{0 . 0 0 0}$ & $\mathbf{0 . 1 2} \pm \mathbf{0 . 0 4}$ & NA $\S$ & 0.99 \\
\hline & Plymouth & $\mathbf{0 . 3 7} \pm \mathbf{0 . 0 1 3}$ & $\mathbf{0 . 7 3} \pm \mathbf{0 . 0 6 5}$ & 0.99 & $\mathbf{0 . 6 7} \pm \mathbf{0 . 1 0}$ & $\mathbf{0 . 1 9} \pm \mathbf{0 . 0 2}$ & $\mathbf{0 . 0 1 2} \pm \mathbf{0 . 0 0 2}$ & $\mathbf{0 . 1 6} \pm \mathbf{0 . 0 7}$ & $\mathbf{N A}$ & 0.99 \\
\hline & \multicolumn{10}{|c|}{ TNT solution phase } \\
\hline \multirow[t]{2}{*}{ 14C-TNT } & Adler & $\mathbf{0 . 5 1} \pm \mathbf{0 . 0 1 5}$ & $\mathbf{0 . 0 8 2} \pm \mathbf{0 . 0 1 8}$ & 0.99 & $\mathbf{0 . 6 3} \pm \mathbf{0 . 0 0}$ & $\mathbf{0 . 5 3} \pm \mathbf{0 . 0 2}$ & $\mathbf{0 . 0 2 3} \pm \mathbf{0 . 0 0 5}$ & $\mathbf{0 . 0 9} \pm \mathbf{0 . 0 0}$ & NA & 0.98 \\
\hline & Plymouth & $\mathbf{0 . 3 8} \pm \mathbf{0 . 0 1 5}$ & $\mathbf{0 . 6 2} \pm \mathbf{0 . 2 2}$ & 0.99 & $\mathbf{0 . 3 8} \pm \mathbf{0 . 1 1}$ & $\mathbf{0 . 6 3} \pm \mathbf{0 . 0 8}$ & $\mathbf{0 . 1 0 1} \pm \mathbf{0 . 0 2 2}$ & $0.41 \pm \mathbf{0 . 2 2}$ & NA & 0.97 \\
\hline TNT & Adler & $\mathbf{0 . 5 1} \pm \mathbf{0 . 0 1 5}$ & $0.082 \pm 0.018$ & 0.99 & $0.46 \pm 0.02$ & $\mathbf{0 . 4 7} \pm \mathbf{0 . 0 7}$ & $\mathbf{0 . 1 9 4} \pm \mathbf{0 . 0 5 7}$ & $\mathbf{0 . 8 2} \pm \mathbf{0 . 5 1}$ & NA & 0.78 \\
\hline \multicolumn{11}{|c|}{ Comp B solution phase } \\
\hline \multirow{2}{*}{${ }^{14} \mathrm{C}-\mathrm{RDX}$} & Adler & $\mathbf{0 . 5 1} \pm \mathbf{0 . 0 0 0}$ & $\mathbf{0 . 1 7} \pm \mathbf{0 . 0 8}$ & 0.99 & $\mathbf{0 . 9 2} \pm \mathbf{0 . 0 4}$ & $\mathbf{0 . 1 7} \pm \mathbf{0 . 0 0}$ & $\mathbf{0 . 0 0 0} \pm \mathbf{0 . 0 0 0}$ & $\mathbf{0 . 0 4} \pm \mathbf{0 . 0 2}$ & NA & 0.99 \\
\hline & Plymouth & $\mathbf{0 . 3 8} \pm \mathbf{0 . 0 0 2}$ & $0.86 \pm 0.22$ & 0.99 & $\mathbf{0 . 5 4} \pm \mathbf{0 . 0 5}$ & $\mathbf{0 . 2 2} \pm \mathbf{0 . 0 2}$ & $\mathbf{0 . 0 0 0} \pm \mathbf{0 . 0 0 0}$ & $\mathbf{0 . 1 6} \pm \mathbf{0 . 1 1}$ & NA & 0.99 \\
\hline \multirow[t]{2}{*}{ HMX } & Adler & $\mathbf{0 . 5 1} \pm \mathbf{0 . 0 0 0}$ & $\mathbf{0 . 1 7} \pm \mathbf{0 . 0 8}$ & 0.99 & $0.87 \pm \mathbf{0 . 0 0}$ & $0.48 \pm 0.01$ & $\mathbf{0 . 0 0 1} \pm \mathbf{0 . 0 0 1}$ & $0.06 \pm 0.01$ & NA & 0.99 \\
\hline & Plymouth & $\mathbf{0 . 3 8} \pm \mathbf{0 . 0 0 2}$ & $0.86 \pm 0.22$ & 0.99 & $0.51 \pm 0.12$ & $\mathbf{0 . 4 3} \pm \mathbf{0 . 0 3}$ & $\mathbf{0 . 0 0 0} \pm \mathbf{0 . 0 0 0}$ & $\mathbf{0 . 1 3} \pm \mathbf{0 . 0 9}$ & NA & 0.98 \\
\hline \multirow{2}{*}{ RDX } & Adler & $0.51 \pm \mathbf{0 . 0 0 0}$ & $\mathbf{0 . 1 7} \pm \mathbf{0 . 0 8}$ & 0.99 & $\mathbf{0 . 8 0} \pm \mathbf{0 . 0 3}$ & $\mathbf{0 . 1 9} \pm \mathbf{0 . 0 1}$ & $\mathbf{0 . 0 1 2} \pm \mathbf{0 . 0 0 2}$ & $\mathbf{0 . 1 9} \pm \mathbf{0 . 1 2}$ & NA & 0.995 \\
\hline & Plymouth & $\mathbf{0 . 3 8} \pm \mathbf{0 . 0 0 2}$ & $0.86 \pm 0.22$ & 0.99 & $\mathbf{0 . 5 0} \pm \mathbf{0 . 0 4}$ & $0.21 \pm 0.02$ & $\mathbf{0 . 0 1 3} \pm \mathbf{0 . 0 0 5}$ & $0.12 \pm 0.06$ & NA & 0.99 \\
\hline \multirow{2}{*}{ TNT } & Adler & $\mathbf{0 . 5 1} \pm \mathbf{0 . 0 0 0}$ & $\mathbf{0 . 1 7} \pm \mathbf{0 . 0 8}$ & 0.99 & 0.38 & 0.60 & 0.268 & 0.45 & NA & 0.84 \\
\hline & Plymouth & $\mathbf{0 . 3 8} \pm \mathbf{0 . 0 0 2}$ & $\mathbf{0 . 8 6} \pm \mathbf{0 . 2 2}$ & 0.99 & $\mathbf{0 . 4 2} \pm \mathbf{0 . 1 3}$ & $\mathbf{0 . 9 8} \pm \mathbf{0 . 1 5}$ & $0.210 \pm 0.015$ & $\mathbf{0 . 1 0} \pm \mathbf{0 . 0 4}$ & NA & 0.98 \\
\hline \multicolumn{11}{|l|}{ Comp B solid } \\
\hline \multirow{2}{*}{$\begin{array}{l}\text { HMX, no } \\
\text { degradation }\end{array}$} & Adler & $\mathbf{0 . 5 1} \pm \mathbf{0 . 0 0 3}$ & $0.068 \pm 0.006$ & 0.99 & NAII & $\mathbf{0 . 3 5} \pm \mathbf{0 . 1 1}$ & NA & NA & $2.8 \pm 1.8$ & 0.64 \\
\hline & Plymo & $\mathbf{0 . 3 7} \pm \mathbf{0 . 0 1 3}$ & 2.29 & 0.96 & NA & $\mathbf{0 . 2 0} \pm \mathbf{0 . 0 3}$ & $\mathbf{N A}$ & NA & $6.4 \pm 3.7$ & 0.84 \\
\hline \multirow{2}{*}{$\begin{array}{l}\text { RDX, fitted } \\
\text { degradation\# }\end{array}$} & Adler & $\mathbf{0 . 5 1} \pm \mathbf{0 . 0 0 3}$ & $0.068 \pm 0.006$ & 0.99 & NA & $0.18 \pm 0.04$ & $0.003 \pm 0.002$ & NA & $29 \pm 22$ & 0.71 \\
\hline & Plymouth & $\mathbf{0 . 3 7} \pm \mathbf{0 . 0 1 3}$ & 2.29 & 0.96 & NA & $\mathbf{0 . 0 5} \pm \mathbf{0 . 0 0}$ & $\mathbf{0 . 0 0 2} \pm \mathbf{0 . 0 0 0}$ & NA & $76 \pm 47$ & 0.95 \\
\hline \multirow{2}{*}{$\begin{array}{l}\text { TNT, fitted } \\
\text { degradation\# }\end{array}$} & Adler & $\mathbf{0 . 5 1} \pm \mathbf{0 . 0 0 3}$ & $\mathbf{0 . 0 6 8} \pm \mathbf{0 . 0 0 6}$ & 0.99 & NA & $\mathbf{0 . 3 5} \pm \mathbf{0 . 1 1}$ & $\mathbf{0 . 0 2 0} \pm \mathbf{0 . 0 0 1}$ & NA & $39 \pm 16$ & 0.75 \\
\hline & Plymouth & $\mathbf{0 . 3 7} \pm \mathbf{0 . 0 1 3}$ & 2.29 & 0.96 & NA & $\mathbf{0 . 2 9} \pm \mathbf{0 . 0 0}$ & $\mathbf{0 . 0 0 8} \pm \mathbf{0 . 0 0 4}$ & NA & $65 \pm 41$ & 0.85 \\
\hline \multirow{2}{*}{$\begin{array}{l}\text { TNT, fixed } \\
\text { degradation } \dagger \dagger\end{array}$} & Adler & $\mathbf{0 . 5 1} \pm \mathbf{0 . 0 0 3}$ & $\mathbf{0 . 0 6 8} \pm \mathbf{0 . 0 0 6}$ & 0.99 & NA & $\mathbf{0 . 2 6} \pm \mathbf{0 . 0 2}$ & NA & NA & $56 \pm 25$ & 0.59 \\
\hline & Plymouth & $\mathbf{0 . 3 7} \pm \mathbf{0 . 0 1 3}$ & 2.29 & 0.96 & NA & $\mathbf{0 . 5 0} \pm \mathbf{0 . 0 1}$ & NA & NA & $634 \pm 445$ & 0.83 \\
\hline
\end{tabular}

$\dagger \theta=$ water content; $\lambda=$ longitudinal dispersivity; $f=$ fraction of sites with instantaneous adsorption; $k_{\mathrm{d}}=$ adsorption coefficient; $\mu_{\mathrm{w}}=$ first-order rate coefficient for dissolved phase, degradation rate (for ${ }^{14} \mathrm{C}$ radiotracer experiments indicates irreversible attenuation); $\omega=$ first-order rate coefficient for two-site nonequilibrium adsorption; $\gamma=$ zero-order rate coefficient for dissolution of solid Comp B.

$\$$ (means \pm standard error; $n=2$ ).

$\$$ Not applicable.

II Because of increased uncertainty in Solid Comp B experiments, values for kinetic sorption parameters $(f$ and $\omega)$ were largely nonsignificant and therefore they were removed from the model.

\# Degradation rate was determined from product concentrations.

$\dagger$ Degradation rate was determined as a sum of rates determined from product concentrations ("fitted degradation") and the irreversible attenuation rate for pure TNT $\left(0.042\right.$ and $0.109 \mathrm{~h}^{-1}$ for TNT for Adler and Plymouth soils, respectively).

et al., 1995; Kaplan and Kaplan, 1982b; Selim et al., 1995). Since degradation cannot be estimated from radiotracer data, unrecovered ${ }^{14} \mathrm{C}$-TNT is assumed to be covalently bound to the soil OM by reactions reported by Thorn et al. (2002). Also, TNT may form coplanar complexes with K-exchanged phyllosilicate clays in soils (Weissmahr et al., 1999); however, in studied soils only 0.5 to $1.2 \%$ of exchange sites were occupied by K. Selim et al. (1995) reported that irreversible attenuation was a dominant retention mechanism of TNT.

In Adler soil, the amount of TNT recovered by HPLC was much lower than ${ }^{14} \mathrm{C}$-TNT recovered since ${ }^{14} \mathrm{C}$-TNT elutes as both TNT and its decomposition products. HPLC showed recovery of 7 to $15 \%$ as TNT and 29 to $35 \%$ as a sum of TNT and its measured products. In Plymouth, HPLC TNT recovery was even lower than in Adler soil with less than 5\% of inflow. Measured products included ADNTs and azoxy compounds in agreement with Comfort et al. (1995) who observed that a significant fraction of TNT was recovered as amino degradates of TNT.

Forty to forty four percent $\left({ }^{14} \mathrm{C}\right.$-TNT recovery minus HPLC TNT and its measured products) in Adler soil and 36 to $39 \%$ in Plymouth soil were unaccounted for, likely as undefined or unmeasured degradation products. TNT mineralization to $\mathrm{CO}_{2}$ is unlikely (Kaplan and Kaplan, 1982a; Speitel et al., 2002).

\section{Solution Phase Composition B}

TNT and RDX from dissolved Comp B behaved like pure TNT and RDX (Fig. 4) with $k_{\mathrm{d}} s$, irreversible attenuation rate, degradation rate, fraction of sites with instantaneous adsorption, and rate of exchange for kinetic sites for ${ }^{14} \mathrm{C}$-RDX radiotracer, RDX, and TNT in Comp B not significantly different from the ones obtained for pure explosives (Table 3).

The only difference was in the rate of irreversible attenuation and mass balance of ${ }^{14} \mathrm{C}-\mathrm{RDX}$ radiotracer in Plymouth soil. Unlike pure ${ }^{14} \mathrm{C}-\mathrm{RDX}$ in Plymouth that exhibited a statistically significant rate of irreversible attenuation $\left(0.012 \pm 0.002 \mathrm{~h}^{-1}\right),{ }^{14} \mathrm{C}$-RDX in Comp B had no significant irreversible attenuation (irreversible attenuation rate, $\mu_{\mathrm{w}}$, was not significantly different from zero). In addition, all of ${ }^{14} \mathrm{C}$-RDX was recovered in Comp B $(105 \pm 0 \%)$, whereas in pure ${ }^{14} \mathrm{C}-\mathrm{RDX}$ some was retained ( 8 to $18 \%$ ). Some competition for irreversible attenuation sites between TNT and RDX is possible, since products of TNT transformation actively react with OM.

The HMX, which was not studied separately, was stable with no significant degradation or irreversible attenuation and $100 \%$ recovery (96 to $103 \%$ ). The HMX $k_{\mathrm{d}} s\left(0.43\right.$ to $\left.0.48 \mathrm{~cm}^{3} \mathrm{~g}^{-1}\right)$ were in general agreement with batch values summarized by Brannon and Pennington (2002). Close agreement between reported batch $k_{\mathrm{d}} s$ for HMX (0.086 to $5.02 \mathrm{~cm}^{3} \mathrm{~g}^{-1}$, median 

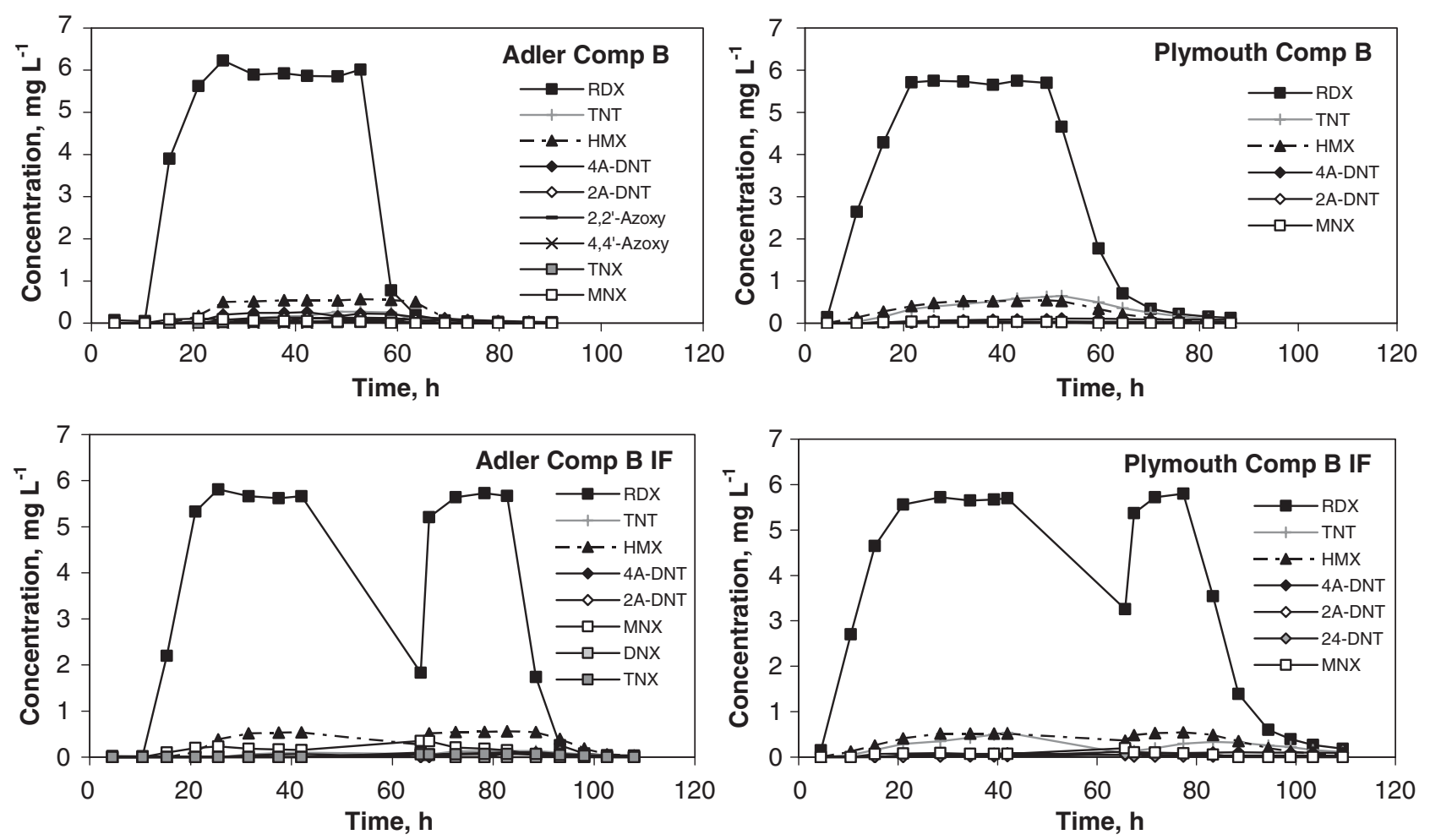

Fig. 4. Breakthrough curves for liquid phase Composition B (Comp B) for Adler and Plymouth soils. IF, interrupted flow; RDX, hexahydro1,3,5-trinitro-1,3,5-triazine; MNX, hexahydro-1-nitroso-3,5-dinitro-1,3,5-triazine; DNX, hexahydro-1,3-dinitroso-5-nitro-1,3,5-triazine; TNX, hexahydro-1,3,5-trinitroso-1,3,5-triazine; HMX, octahydro-1,3,5,7-tetranitro-1,3,5,7-tetrazocine; TNT, trinitrotoluene; 2-ADNT-2-amino-4, 6,-dinitrotoluene; 4-ADNT, 4-amino-2,6,-dinitrotoluene; 2,2'-Azoxy, 4,4',6,6'-tetranitro-2,2' -azoxytoluene; 4,4' -Azoxy, 2,2',6,6'-tetranitro-4, 4 '-azoxytoluene.

$0.77 \mathrm{~cm}^{3} \mathrm{~g}^{-1}$, average $1.62 \mathrm{~cm}^{3} \mathrm{~g}^{-1}$ ) (Myers et al., 1998; Brannon et al., 1999; Pennington et al., 1999) and columndetermined values can be explained by the absence of irreversible attenuation.

Degradation products of TNT accounted for $65 \%$ of outflow in Adler soil and 25\% in Plymouth soil. They included ADNTs, which predominated, in agreement with Selim et al. (1995), and azoxy compounds. There was more 4ADNT than 2ADNT in agreement with Comfort et al. (1995). Furthermore, 4ADNT exhibited an earlier breakthrough. This can be explained by higher partition coefficients for 2ADNT (Pennington and Patrick, 1990), and greater production of 4ADNT because biotic reduction of nitro group in para position is more prevalent. Kaplan and Kaplan (1982a) reported that 4ADNT accounted for the majority of the two amines in compost spiked with TNT.

Degradation products of RDX were only a small part of the outflow (Table 2): 0.4 to $4 \%$ of RDX input (0.4 to $5 \%$ of the RDX outflow). The fraction of products doubled in interrupted flow experiments, as additional time allowed degradation to proceed further. Hexahydro-1-nitroso-3,5-dinitro-1,3,5-triazine (MNX) was the only detected degradation product in Plymouth soil. In Adler soil, DNX (hexahydro-1,3-dinitroso-5-nitro-1,3,5triazine) and TNX (hexahydro-1,3,5-trinitroso-1,3,5triazine) were detected. Concentrations of all degradation products increased in the outflow after flow interruption. Degradation pathways of RDX and TNTwere mod- eled, but are not reported, since parameter estimates were nonsignificant.

\section{Solid Composition B}

Breakthrough curves from solid Comp B indicated that despite the small range of particle sizes, variability in dissolution rate of Comp B among the experiments was significant (Fig. 5). For two experiments outflow concentrations decreased in time, possibly due to a decrease in dissolution rate as smaller particles were dissolved. Smaller particles with a larger surface area dissolve faster due to greater contact with solution (Lynch et al., 2002a). The sharp initial peak observed for the interrupted flow experiment in Adler soil can be explained by the presence of microscopic Comp B particles on the surface of the principle particles as observed by Phelan et al. (2003). As dissolution is strongly affected by particle size, microscopic particles will dissolve fastest and result in a sharp increase in solution concentration. Another prominent feature of the breakthrough curves was similarity in outflow concentrations of TNT and RDX, contrary to what was observed for dissolved Comp B (Fig. 4) and to observations of groundwater concentrations in the field (Clausen et al., 2004). Variance from the field results was explained by the small length of the column and limited residence time of solution. Longer residence would cause a greater change in solution concentration of TNT than RDX due to 

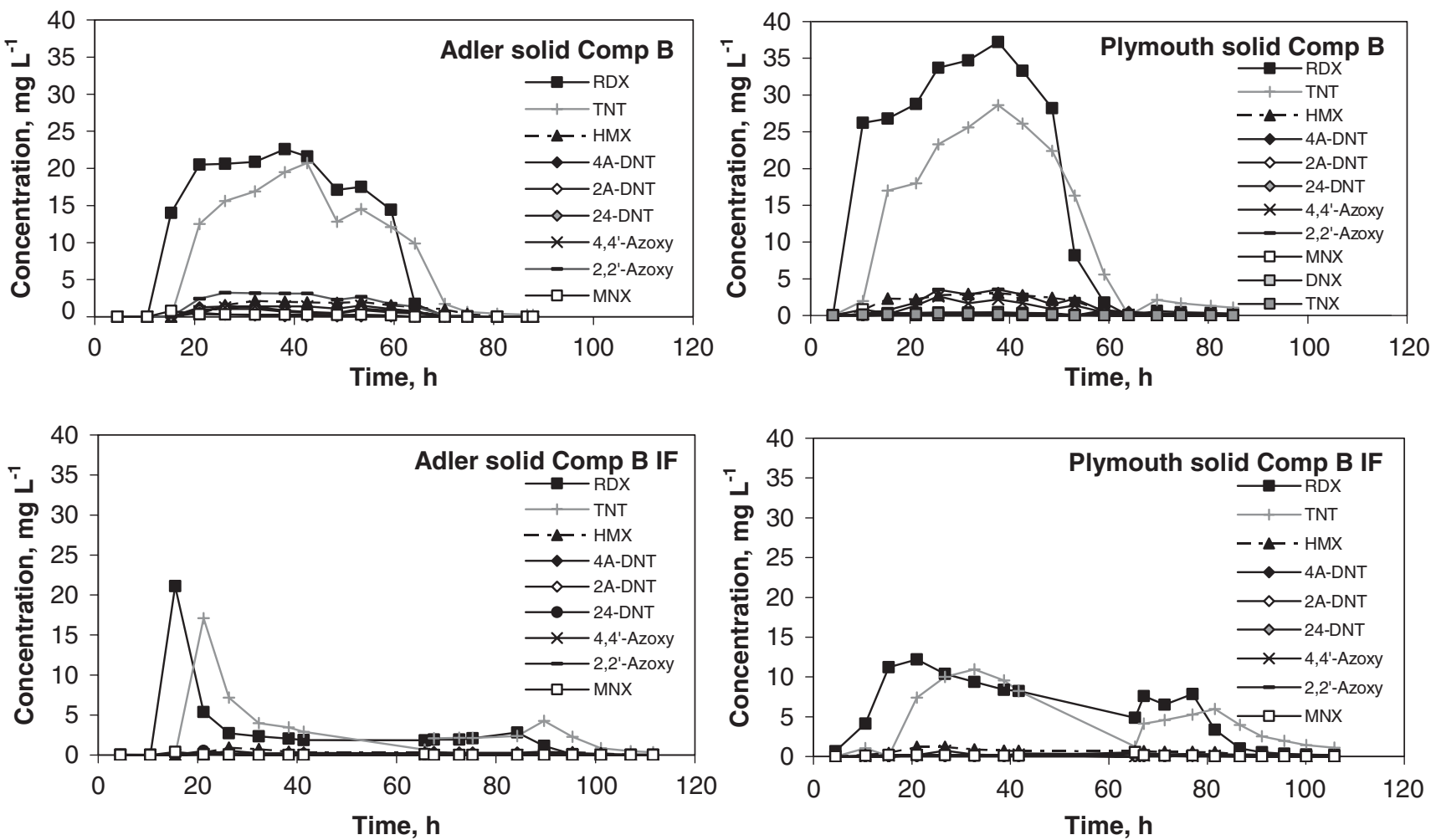

Fig. 5. Breakthrough curves for solid phase Composition B (Comp B) for Adler and Plymouth soils. IF, interrupted flow; RDX, hexahydro1,3,5-trinitro-1,3,5-triazine; MNX, hexahydro-1-nitroso-3,5-dinitro-1,3,5-triazine; DNX, hexahydro-1,3-dinitroso-5-nitro-1,3,5-triazine; TNX, hexahydro-1,3,5-trinitroso-1,3,5-triazine; HMX, octahydro-1,3,5,7-tetranitro-1,3,5,7-tetrazocine; TNT, trinitrotoluene; 2-ADNT, 2-amino-4,6,dinitrotoluene; 4-ADNT, 4-amino-2,6,-dinitrotoluene; 2,2' -Azoxy, 4,4',6,6'-tetranitro-2,2' -azoxytoluene; 4,4' -Azoxy, 2,2',6,6'-tetranitro-4,4' azoxytoluene.

differences in degradation rates. Longer soil profiles enhance the contribution of reversible sorption and irreversible attenuation. Difference between solid and dissolved Comp B experiments indicated that TNT has a greater dissolution rate than RDX.

As an excess of Comp B was used, no reliable measure of a source term was available to model transport using HYDRUS-1D. Therefore, degradation had to be determined to estimate dissolution of Comp B. Outflow concentrations of HMX in dissolved Comp B experiments were similar to inflow concentrations. Based on this and the absence of HMX degradation products in dissolved and solid Comp B tests, degradation of HMX from solid Comp B was assumed to be negligible and was, therefore, set at zero ("no degradation" in Table 3). For RDX, which had some decomposition, but no irreversible attenuation in dissolved Comp B experiments, degradation was determined from the concentration of degradation products assuming that the products did not further decompose ("fitted degradation" in Table 3). For TNT, degradation rate was also determined from product concentrations. However, unlike RDX, TNT exhibited irreversible attenuation. Therefore, the irreversible attenuation rate observed for pure TNT was added to the degradation rate determined from product concentrations to give a total degradation rate $(0.0424$ and $0.1091 \mathrm{~h}^{-1}$ for TNT for Adler and Plymouth soils, respectively) ("fixed degradation" in Table 3). Irreversible attenuation was assumed to be the same for TNT in solid Comp B as for pure TNT because total degradation rates in the pure system and in the dissolved Comp B system were similar. Degradation rates of TNT and RDX determined from product outflow concentration were lower than determined for dissolved Comp B and pure systems (Table 3), but this was supported by the fact that concentrations of products relative to parent compounds were smaller in the solid Comp B experiments. Greater concentrations of TNT and RDX in the solid Comp B experiment may have caused a reduction in microbial populations (Comfort et al., 1995) and suppression of biotic reduction that exceeds abiotic reduction of TNT (Pennington and Patrick, 1990).

When the above approach was applied to the data, simulated dissolution rates (Table 3 ) varied between the experiments, reflecting variability in outflow. However, a highly significant correlation $(P>F<0.01)$ existed between HYDRUS-1D-estimated dissolution rates of HMX and RDX and a significant correlation $(P>F<$ 0.05 ) between RDX and TNT. This supported the accuracy of HYDRUS estimates of dissolution rates of Comp B and indicated that dissolution rates of explosives in a mix are linked. Dissolution rate was the highest for TNT and lowest for HMX. According to Brannon and Pennington (2002) when tested alone, TNT has the highest dissolution rate $\left(4164 \mu \mathrm{g} \mathrm{cm}{ }^{-2} \mathrm{~h}^{-1}\right)$, followed by HMX (702 $\left.\mu \mathrm{g} \mathrm{cm}^{-2} \mathrm{~h}^{-1}\right)$ and RDX (361 $\mu \mathrm{g}$ $\left.\mathrm{cm}^{-2} \mathrm{~h}^{-1}\right)$. Several studies indicated that the dissolution rate of individual explosives is decreased by being pres- 
ent in formulations, whereas solubility is not affected (Lynch et al., 2002b; Phelan et al., 2002; Taylor et al., 2004). In this study, the link between dissolution rates of different components of Comp B was analyzed by comparing slopes of regressions between dissolution rates of RDX, TNT, and HMX (Table 4) with other relevant properties of studied explosives normalized to RDX: individual dissolution rate, measured content in Comp $\mathrm{B}$, and solubility. None of the listed properties gave a good explanation for the dissolution rates; however, a product of individual dissolution rate and explosives content in Comp B was in very good agreement with HYDRUS-1D estimates of dissolution rates in the formulation. This can be explained by dissolution being related to the surface area, that for each individual compound decreased proportionally to its content in the formulation.

Adsorption coefficients for HMX, RDX, and TNT determined from solid Comp B were generally smaller than in dissolved Comp B. Differences were significant for Plymouth soil and for TNT in Adler soil. Two processes can explain this difference, saturation of sorption sites at high concentrations (inflow in dissolved Comp B was below $10 \mathrm{mg} \mathrm{L}^{-1}$ whereas in solid Comp B outflow was as high as $40 \mathrm{mg} \mathrm{L}^{-1}$ ), and competition between RDX and TNT at high concentrations for nonspecific sorption sites. Both possibilities are supported by previous reports. Comfort et al. (1995) observed nonlinear sorption of TNT and higher sorption coefficients at low concentrations, whereas Haderlein et al. (1996) reported competitive adsorption of nitroaromatic compounds.

\section{CONCLUSIONS}

A saturated column transport study was conducted to evaluate transport parameters for RDX, TNT, and solution and solid Comp B for two soils. Sorption coefficients were estimated and contribution of transformation and irreversible sorption was established. RDX was more mobile than TNT because RDX had smaller reversible sorption, irreversible attenuation, and degradation.

Combining column flow-through studies with numerical analysis of outflow concentrations of explosives and an inert tracer allowed separation of the contributions of physical and chemical nonequilibrium processes. Whereas for studied soils with uniform particle-size physical nonequilibrium was negligible, chemical non-

Table 4. Estimated high explosives dissolution rate from solid Comp $B$ and other relevant properties of studied explosives normalized to RDX.

\begin{tabular}{lccrl}
\hline Explosives properties & RDX & HMX & TNT & Source \\
\hline $\begin{array}{l}\text { Estimated dissolution } \\
\text { rate from solid Comp B }\end{array}$ & 1.00 & 0.08 & 7.68 & current study \\
$\begin{array}{l}\text { Individual dissolution rate } \\
\text { Content in Comp B }\end{array}$ & 1.00 & 1.94 & 11.53 & $\begin{array}{l}\text { (Brannon and } \\
\text { Pennington, 2002) }\end{array}$ \\
$\begin{array}{l}\text { Conten } \\
\text { Solubility at 20 }\end{array}$ & 1.00 & 0.06 & 0.68 & $\begin{array}{c}\text { current study } \\
\text { (Brannon and } \\
\text { Pennington, 2002) }\end{array}$ \\
$\begin{array}{l}\text { Individual dissolution } \\
\text { rate } \times \text { explosive } \\
\text { content in Comp B }\end{array}$ & 1.00 & 0.12 & 7.79 & \\
\hline
\end{tabular}

equilibrium (kinetic sorption) contributed to transport and distribution of both RDX and TNT. The contribution of chemical nonequilibrium was confirmed by interrupted flow experiments.

The behavior of dissolved Comp B was similar to that of pure RDX and TNT. Estimated adsorption and degradation rates for RDX, TNT, and HMX were generally smaller for solid Comp B than for dissolved explosives in column and batch studies. Therefore, using distribution coefficients from batch studies and transport parameters determined for pure explosives in solution can underestimate transport of formulations. However, great variability in outflow concentrations in experiments with solid phase Comp B indicated that dissolution was controlling transport processes. The dissolution rate of Comp B was affected by the dissolution rate of pure compounds and by their fraction in Comp B.

\section{ACKNOWLEDGMENTS}

This study was funded by the U.S. Army Corps of Engineers, Environmental Quality Technology Program. M. John Cullinane, Program Manager. Work of J. Šimunek was supported by the Terrestrial Sciences Program of the Army Research Office (Terrestrial Processes and Landscape Dynamics and Terrestrial System Modeling and Model Integration). Authors are grateful to T. Myers of ERDC, Vicksburg, MS for his review of the manuscript. Disclaimer: Permission has been granted by the Chief of Engineers to publish this report.

\section{REFERENCES}

Achtnich, C., and H. Lenke. 2001. Stability of immobilized 2,4,6trinitrotoluene metabolites in soil under long-term leaching conditions. Environ. Toxicol. Chem. 20:280-283.

Ainsworth, C.C., S.D. Harvey, J.E. Szecsody, M.A. Simmons, V.I. Cullinan, C.T. Resch, and G.M. Mong. 1993. Relationship between the leachability characteristics of unique energetic compounds and soil properties. Final Report, Project Order No. 91PP1 800. U.S. Army Biomedical Research and Development Laboratory, Fort Detrick, Frederick, MD.

Balakrishnan, V.K., F. Monteil-Rivera, M.A. Gautier, and J. Hawari. 2004. Sorption and stability of the polycyclic nitramine explosive CL-20 in soil. J. Environ. Qual. 33:1362-1368.

Brannon, J.M., D.D. Adrian, J.C. Pennington, T.E. Myers, and C.A. Hayes. 1992. Slow release of PCB, TNT, and RDX from soils and sediments. Technical Report EL-92-38. U.S. Army Engineer Waterways Experiment Station, Vicksburg, MS.

Brannon, J.M., P.N. Deliman, J.A. Gerald, C.E. Ruiz, C.B. Price, C. Hayes, S. Yost, and M. Qasim. 1999. Conceptual model and process descriptor formulations for fate and transport of UXO. Technical Report IRRP-99-1. U.S. Army Engineer Waterways Experiment Station, Vicksburg, MS. Available at http://libweb.wes.army.mil/ uhtbin/hyperion/TR-IRRP-99-1.pdf (verified 8 Aug. 2006).

Brannon, J.M., and J.C. Pennington. 2002. Environmental fate and transport process descriptors for explosives. Technical report TR-02-10. U.S. Army Corps of Engineers, Engineer Research and Development Center, Vicksburg, MS. Available at http://libweb.wes. army.mil/uhtbin/hyperion/EL-TR-02-10.pdf (verified 8 Aug. 2006).

Brannon, J.M., C.B. Price, and C.A. Hayes. 1998. Abiotic transformation of TNT in montmorillonite and soil suspensions under reducing conditions. Chemosphere 36:1453-1462.

Brannon, J.M., C.B. Price, C. Hayes, and S.L. Yost. 2002. Aquifer soil cation substitution and adsorption of TNT, RDX, and HMX. Soil Sediment Contam. 11:327-338.

Brannon, J.M., C.B. Price, S.L. Yost, C.A. Hayes, and B. Porter. 2005. Comparison of environmental fate and transport process descriptors of explosives in saline and freshwater systems. Mar. Pollut. Bull. 50:247-251. 
Clausen, J., J. Robb, D. Curry, and N. Korte. 2004. A case study of contaminants on military ranges: Camp Edwards, Massachusetts, USA. Environ. Pollut. 129:13-21.

Comfort, S.D., P.J. Shea, L.S. Hundal, Z. Li, B.L. Woodbury, J.L. Martin, and W.L. Powers. 1995. TNT transport and fate in contaminated soil. J. Environ. Qual. 24:1174-1182.

Fesch, C., W. Simon, S.B. Haderlein, P. Reichert, and R.P. Schwarzenbach. 1998. Nonlinear sorption and nonequilibrium solute transport in aggregated porous media: Experiments, process identification, and modeling. J. Contam. Hydrol. 31:373-407.

Fortin, J., M. Flury, W.A. Jury, and T. Streck. 1997. Rate-limited sorption of simazine in saturated soil columns. J. Contam. Hydrol. 25:219-234.

Gaber, H.M., W.P. Inskeep, S.D. Comfort, and J.M. Wraith. 1995. Nonequilibrium transport of atrazine through large intact soil cores. Soil Sci. Soc. Am. J. 59:60-67.

Gee, G.W., and D. Or. 2002. Particle-size analysis. p. 255-294. In J.H Dane and G. Clarke Topp (ed.) Methods of soil analysis. Part 4 Physical methods. SSSA, Madison, WI.

Haderlein, S.B., K.W. Weissmahr, and R.P. Schwarzenbach. 1996. Specific adsorption of nitroaromatic explosives and pesticides to clay minerals. Environ. Sci. Technol. 30:612-622.

Jenkins, T.F., G.C. Topp, A.D. Hewitt, C.L. Grant, S. Thiboutat, G. Ampleman, M.E. Walsh, T.A. Ranney, C.A. Ramsey, A.J. Palazzo, and J.C. Pennington. 2006. Identity and distribution of residues of energetic compounds at army live-fire training ranges. Chemosphere 63:1280-1290.

Kaplan, D.L., and A.M. Kaplan. 1982a. Thermophilic biotransformations of 2,4,6-trinitrotoluene under simulated composting conditions. Appl. Environ. Microbiol. 44:757-760.

Kaplan, D.L., and A.M. Kaplan. 1982b. 2,4,6-Trinitrotoluene-surfactant complexes: Decomposition, mutagenicity, and soil leaching studies. Environ. Sci. Technol. 16:566-571.

Lynch, J.C., J.M. Brannon, and J.J. Delfino. 2002a. Dissolution rates of three high explosive compounds: TNT, RDX, and HMX. Chemosphere 47:725-734.

Lynch, J.C., J.M. Brannon, and J.J. Delfino. 2002b. Effects of component interactions on the aqueous solubilities and dissolution rates of the explosive formulations octol, composition B, and LX14. J. Chem. Eng. Data 47:542-549.

Marquardt, D.W. 1963. An algorithm for least-squares estimation of nonlinear parameters. J. Soc. Ind. Appl. Math. 11:431-441.

Murali, V., and L.A.G. Aylmore. 1980. No-flow equilibration and adsorption dynamics during ionic transport in soils. Nature 283:467-469.

Myers, T.E., J.M. Brannon, J.C. Pennington, W.M. Davis, K.F. Myers, D.M. Townsend, M.K. Ochman, and C.A. Hayes. 1998. Laboratory studies of soil sorption/transformation of TNT, RDX, and HMX Technical Report IRRP-98-8. U.S. Army Engineer Waterways Experiment Station, Vicksburg, MS. Available at http://libweb.wes. army.mil/uhtbin/hyperion/TR-IRRP-98-8.pdf (verified 8 Aug. 2006).

Pennington, J.C., and J.M. Brannon. 2002. Environmental fate of explosives. Thermochim. Acta 384:163-172.

Pennington, J.C., D. Gunnison, D.W. Harrelson, J.M. Brannon, M. Zakikhani, T.F. Jenkins, J.U. Clarke, C.A. Hayes, T. Myers, E. Perkins, D. Ringelberg, D.M. Townsend, H. Fredrickson, and J.H. May. 1999. Natural attenuation of explosives in soil and water systems at Department of Defense Sites: Interim report. Technical Report EL-99-8. U.S. Army Engineer Waterways Experiment Station, Vicksburg, MS.

Pennington, J.C., T.F. Jenkins, G. Ampleman, S. Thiboutot, J.M. Brannon, J. Lynch, T.A. Ranney, J.A. Stark, M.E. Walsh, J. Lewis, C.A. Hayes, J.E. Mirecki, A.D. Hewitt, N. Perron, D. Lambert, J. Clausen, and J.J. Delfino. 2002. Distribution and fate of energetics on DoD test and training ranges: Interim Report 2. Technical Report ERDC TR-02-8. U.S. Army Corps of Engineers, Washington, DC. Available at http://libweb.wes.army.mil/uhtbin/hyperion/ TR-02-8-2.pdf (verified 8 Aug. 2006)

Pennington, J.C., and W.H. Patrick. 1990. Adsorption and desorption of 2,4,6-trinitrotoluene by soils. J. Environ. Qual. 19:559-567.

Pennington, J.C., B. Silverblatt, K. Poe, C.A. Hayes, and S. Yost. 2005. Explosive residues from low-order detonations of artillery munitions. p. 34-54. In Distribution and fate of energetics on DoD test and training ranges: Report 5. ERDC TR-05-2. U.S. Army Engineer Research and Development Center, Vicksburg, MS.
Phelan, J.M., J.V. Romero, J.L. Barnett, and D.R. Parker. 2002. Solubility and dissolution kinetics of Composition B explosive in water. SAND Report SAND2002-2420. Sandia National Laboratories, Albuquerque, NM.

Phelan, J.M., S.W. Webb, J.V. Romero, J.L. Barnett, F. Griffin, and M. Eliassi. 2003. Measurement and modeling of energetic material mass transfer to soil pore water. Project CP-1227 Annual Technical Report SAND2003-0153. Sandia National Laboratories, Albuquerque, NM.

Price, C.B., J.M. Brannon, and C. Hayes. 1997. Effects of redox potential and $\mathrm{pH}$ on TNT transformations in soil-water slurries. J. Environ. Eng. 123:988-992.

Price, C.B., J.M. Brannon, S.L. Yost, and C.A. Hayes. 2000. Adsorption and transformation of explosives in low-carbon aquifer soils Technical Report ERDC/EL TR-00-11. Engineer Research and Development Center Environmental Laboratory, Vicksburg, MS. Available at http://libweb.wes.army.mil/uhtbin/hyperion/EL-TR00-11.pdf (verified 8 Aug. 2006).

Price, C.B., J.M. Brannon, S.L. Yost, and C.A. Hayes. 2001a. Adsorption and transformation of RDX in low-carbon aquifer soils. Technical Report ERDC/EL TR-01-19. Engineer Research and Development Center Environmental Laboratory, Vicksburg, MS Available at http://libweb.wes.army.mil/uhtbin/hyperion/EL-TR01-19.pdf (verified 8 Aug. 2006).

Price, C.B., J.M. Brannon, S.L. Yost, and C.A. Hayes. 2001b. Relationship between redox potential and $\mathrm{pH}$ on RDX transformation in soil-water slurries. J. Environ. Eng. 127:26-31.

Selim, H.M., J.M. Davidson, and R.S. Mansell. 1976. Evaluation of a two-site adsorption-desorption model for describing solute transport in soils. Summer Computer Simulation Conference Proceedings. Nat. Sci. Found., Washington, DC.

Selim, H.M., S.K. Xue, and I.K. Iskandar. 1995. Transport of 2,4,6trinitrotoluene and hexahydro-,3,5-trinitro-1,3,5-triazine in soils. Soil Sci. 160:328-339.

Šimunek, J., and J.W. Hopmans. 2002. Parameter optimization and nonlinear fitting. p. 139-157. In J.H. Dane and G.C. Topp (ed.) Methods of soil analysis. Part 1. Physical methods. Third ed. SSSA, Madison, WI.

Šimunek, J., D. Jacques, J.W. Hopmans, M. Inoue, M. Flury, and M.T. van Genuchten. 2002. Solute transport during variably-saturated flow: Inverse methods. p. 1435-1449. In J.H. Dane and G.C. Topp (ed.) Methods of soil analysis. Part 1. Physical methods. Third ed. SSSA, Madison, WI

Šimunek, J., M.T. van Genuchten, and M. Šejna. 2005. The HYDRUS1D software package for simulating the one-dimensional movement of water, heat, and multiple solutes in variably-saturated media. Version 3.0. Department of Environmental Sciences, University of California Riverside, Riverside, CA.

Singh, J., S.D. Comfort, L.S. Hundal, and P.J. Shea. 1998. Long-term RDX sorption and fate in soil. J. Environ. Qual. 27:572-577.

Speitel, G.E., H. Yamamoto, R.L. Autenrieth, and T. McDonald. 2002. Laboratory fate and transport studies of high explosives at the Massachusetts Military Reservation. Technical Report. AMEC Earth and Environmental, Westford, MA.

Taylor, S., J. Lever, L. Perovich, K.L. Bjella, and B. Packer. 2004. Modelling the dissolution of Composition B. SERDP Proceedings, Washington, DC

Thorn, K.A., J.C. Pennington, and C.A. Hayes. 2002. M-15 NMR investigation of the reduction and binding of TNT in an aerobic bench scale reactor simulating windrow composting. Environ. Sci. Technol. 36:3797-3805

Tucker, W.A., G.J. Murphy, and E.D. Arenberg. 2002. Adsorption of RDX to soil with low organic carbon: Laboratory results, field observations, remedial implications. Soil Sediment Contam. 11: 809-826.

USEPA. 1986. Cation-exchange capacity of soils (sodium acetate). SW846, Method 9081. Office of Solid Waste and Emergency Response, Washington, DC.

USEPA. 1994. Nitroaromatics and nitramines by HPLC. Second Update SW846, Method 8330. Office of Solid Waste and Emergency Response, Washington, DC.

USEPA. 1997. Administrative order for response action EPA docket number SDWA-1-97-1030, USEPA Region 1 in the matter of training range and impact area, Massachusetts military reservation. 
USEPA, Washington, DC. Available at http://groundwaterprogram. army.mil/groundwater/admin/orders/Ao1.pdf (verified 8 Aug. 2006). van Genuchten, M.T., and R.J. Wagenet. 1989. Two-site/two-region models for pesticide transport and degradation: Theoretical development and analytical solutions. Soil Sci. Soc. Am. J. 53: $1303-1310$

Weissmahr, K.W., M. Hildenbrand, R.P. Schwarzenbach, and S.B. Haderlein. 1999. Laboratory and field scale evaluation of geo- chemical controls on groundwater transport of nitroaromatic ammunition residues. Environ. Sci. Technol. 33:2593-2600.

Xue, S.K., I.K. Iskandar, and H.M. Selim. 1995. Adsorptiondesorption of 2,4,6-trinitrotoluene and hexahydro-1,3,5-triazine in soils. Soil Sci. 160:317-327.

Yamamoto, H., M.C. Morley, G.E. Speitel, and J. Clausen. 2004. Fate and transport of high explosives in a sandy soil: Adsorption and desorption. Soil Sediment Contam. 13:459-477. 